\title{
Effectiveness of kinesiotaping on diaphragm thickness, diaphragmatic thickening fraction, and intercostal muscle thickness in patients undergoing mechanical ventilation: a pilot study
}

\author{
Burcu Metin Ökmen, Korgün Ökmenْ \\ ${ }^{1}$ Department of Physical Medicine and Rehabilitation, University of Health Sciences, Bursa Yüksek Ihtisas Training and Research \\ Hospital, Bursa, Turkey \\ ${ }^{2}$ Department of Anesthesiology and Reanimation, University of Health Sciences, Bursa Yüksek Ihtisas Training and Research Hospital, \\ Bursa, Turkey
}

DOI: $10.18621 /$ eurj.373465

\begin{abstract}
Objective: We aimed to evaluate the effects of kinesiotaping applied on the chest wall on the diaphragmatic muscle and intercostal muscles in patients receiving mechanical ventilation.

Methods: In this prospective, randomized, controlled, double-blind study, 24 patients who underwent mechanical ventilation in the intensive care unit were included the study. Randomization was used to identify the side of patients that the kinesiotaping was applied to. Group 1: side that kinesiotaping was applied $(n=24)$ and Group 2 (control group): side that kinesiotaping was not applied $(\mathrm{n}=24)$. Kinesiotaping was changed in every 3 day. Thicknesses of diaphragmatic muscle, seventh intercostal muscle and ninth intercostal muscle were evaluated by using ultrasound in pretreatment, third day, sixth day and ninth day.

Results: In both groups; a statistically significant decrease was found in all the evaluation parameters at all the measurement times when compared to the pretreatment values $(p<0.05)$. On the third day and sixth day; a statistically significant difference was found in favor of group 1 in all the evaluation parameters except thickness of seventh intercostal muscle $(p<0.05)$. On the ninth day; there was no statistically significant difference between the two groups $(p>0.05)$.

Conclusion: In conclusion, our study results showed that kinesiotaping decelerated the decrease in the diaphragmatic muscle and the intercostal muscles thickness until sixth day.

Keywords: Kinesiotaping, diaphragmatic muscle thickness, intercostal muscles thickness, pulmonary rehabilitation, mechanical ventilation
\end{abstract}

Received: January 1, 2018; Accepted: February 15, 2018; Published Online: April 5, 2018

A bout $40 \%$ of patients in the intensive care unit (ICU) require mechanical ventilatory support [1]. Ventilator-induced diaphragmatic dysfunction (VIDD) is defined as the loss of diaphragmatic force- generating capacity associated with the use of mechanical ventilation [1-3]. Immobility of the diaphragm for protection during controlled mechanical ventilation is thought to play a role in the

Address for correspondence: Burcu Metin Ökmen, MD., University of Health Sciences, Bursa Yüksek Ihtisas Training and Research Hospital, Department of Physical Medicine and Rehabilitation, Mimar Sinan Mah., Emniyet Street, Ylldırım, Bursa, Turkey

E-mail: burcumetinokmen@gmail.com,Tel: +902242955000,Fax: +902242955497 
development of VIDD [4]. In addition, imbalance in protein production and degradation as well as reactive oxygen species (ROS) as a result of mitochondrial dysfunction have been also shown to be involved in the pathogenesis of diaphragmatic dysfunction [5].

Approximately 20 to $25 \%$ of patients on mechanical ventilation experience difficulty in weaning from mechanical ventilation and VIDD is one of the most common reasons [1-3]. It has been accepted as the most specific "side effect" of prolonged mechanical ventilation [4]. Although the condition has been termed as VIDD, intercostal muscles along with major respiratory muscles (diaphragm) are thought to be involved to a certain extent [4-7]. Esophageal and gastric balloons, phrenic nerve stimulation, diaphragmatic biopsy, and ultrasonography are commonly used in the diagnosis of diaphragmatic atrophy [1, 8-10]. Ultrasound-guided detection of diaphragmatic atrophy allows measurement of diaphragmatic thickening and evaluation of the diaphragmatic function [11]. Intercostal muscle exercises, various mechanical ventilator settings, phrenic nerve stimulation, and drugs are used to prevent development of VIDD [12].

Kinesiotaping, which was first developed by Kenso Kase, is used in the treatment of musculoskeletal system disorders, sports injuries, and neurological and pediatric diseases. The kinesiotape is a thin, latex-free, elastic adhesive and it stretches up to the $40-60 \%$ of its original length; its structure resembles elastic features of the human skin $[13,14]$. Skin is elevated with kinesiotaping and this increases subcutaneous interstitial area and therefore increases circulation and mobility. Increased circulation and mobility in turn decreases inflammation in the treated area. This treatment therefore aims at reducing pain, increasing performance, re-educating neuromuscular system, preventing injury, and accelerating circulation and tissue healing [13-17]. The treatment by applying a constant pulling force improves blood and lymph circulation by producing proprioceptive stimulation in the nerve endings $[13,14,18]$. In addition, there are also studies suggesting that the method sends signals to the central nervous system by stimulating mechanoreceptors and increases proprioception through a positional stimulation in the applied area [19-21]. There are also some side effects of the kinesiotaping. Skin that is applied depending on the use of kinesiology band reactions can be seen. These are allergic reactions or may be in the form of local irritation [14].

Kinesiotaping has been employed for the purpose of increasing the respiratory capacity [22]. Additionally there are several studies which suggested muscle strengthening by kinesiotaping [23, 24]. However, we could not find any report evaluated the effect of kinesiotaping on the respiratory muscle thickness in the literature. In the present study, we aimed to evaluate the effects of kinesiotaping applied on the chest wall on the diaphragmatic muscle and intercostal muscles in patients receiving mechanical ventilation.

\section{METHODS}

In this prospective, randomized, controlled, double-blind study, a total of 40 patients who were requiring mechanical ventilation were evaluated for eligibility after local ethics committee approval (The decision number is 2011-KAEK-25 2016/20-01). The study was conducted in accordance with the principles of Declaration of Helsinki.

\section{Patient selection}

Patients who were given mechanical ventilation in the intensive care unit between the ages of 20-70 and were approved by their relatives were included in the study. Patients with chronic lung disease, a body mass index (BMI) greater than 30, neuromuscular disease, and who received more than 24 hours of mechanical ventilation therapy within 6 months were excluded from the study. Patients who connected mechanical ventilation for less than 72 hours during testing were dropped out from the study.

Sixteen patients were excluded from the study and the reasons were given in the Figure 1. Twenty four patients who were eligible for the study were included to the study. Forms detailing the patients' demographic characteristics and pre-treatment (D0) measurements were completed.

\section{Randomization}

A computer-generated random number table was used to randomize which side of patients the kinesiotaping was to be applied to. Group 1: 

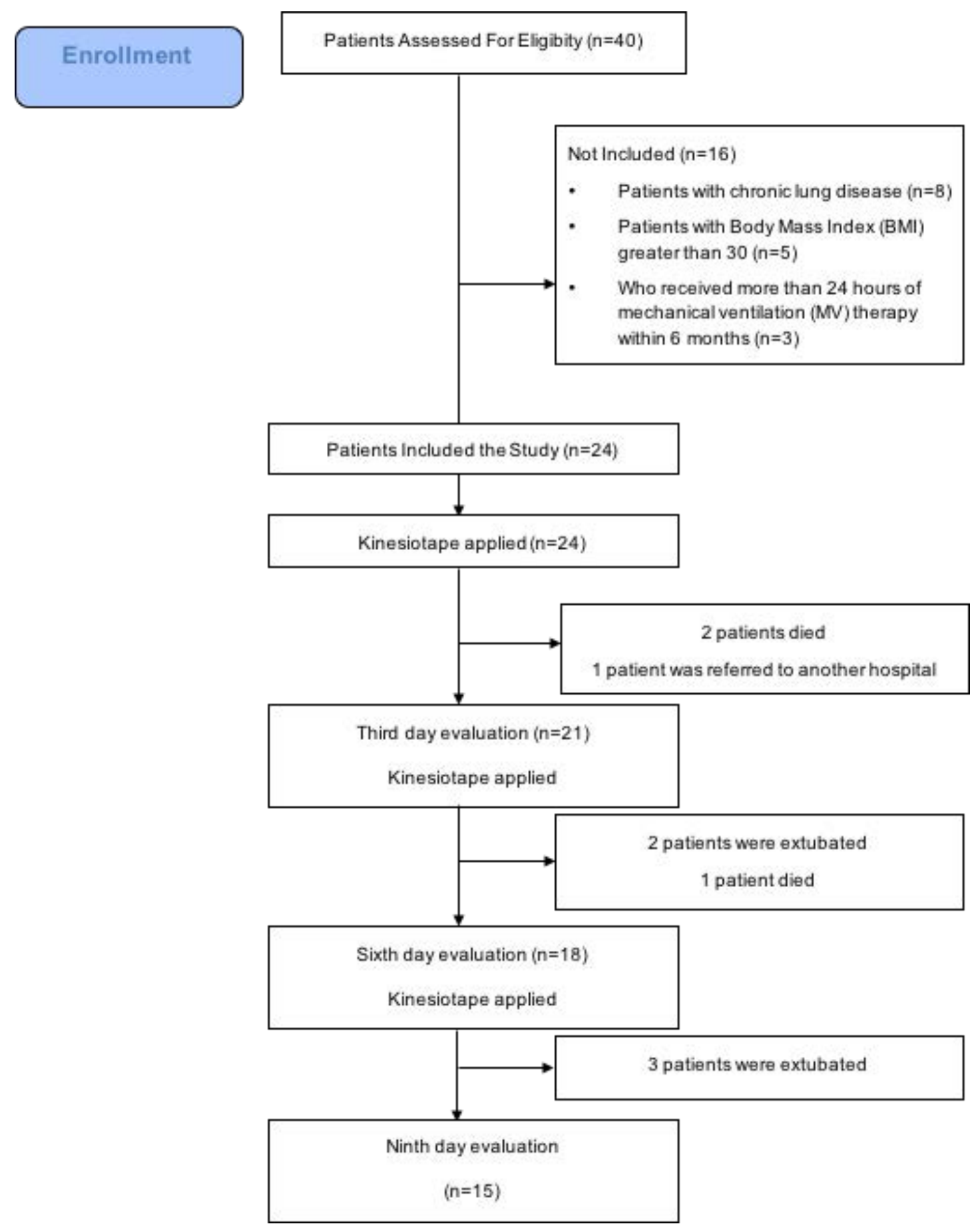

Figure 1. Flow chart of the study.

kinesiotaping applied side $(\mathrm{n}=24)$ and Group 2 kinesiotaping application. Kinesiotaping was applied (control group): kinesiotaping not applied side $(\mathrm{n}=24)$ unilaterally. The other side of the chest wall was used (Figure 1). as the control group. Kinesiotaping was changed in every 3 day by a certificated physiatrist who has

\section{Interventions} previously attended the kinesiotaping training course.

Kinesio Tex Gold (Kinesio Tex Gold, Kinesio ${ }^{\circledR}$; It was applied by the same physiatrist. When the Albuquerque, New Mexico) was used for patients were at the end of the expiration, it was 


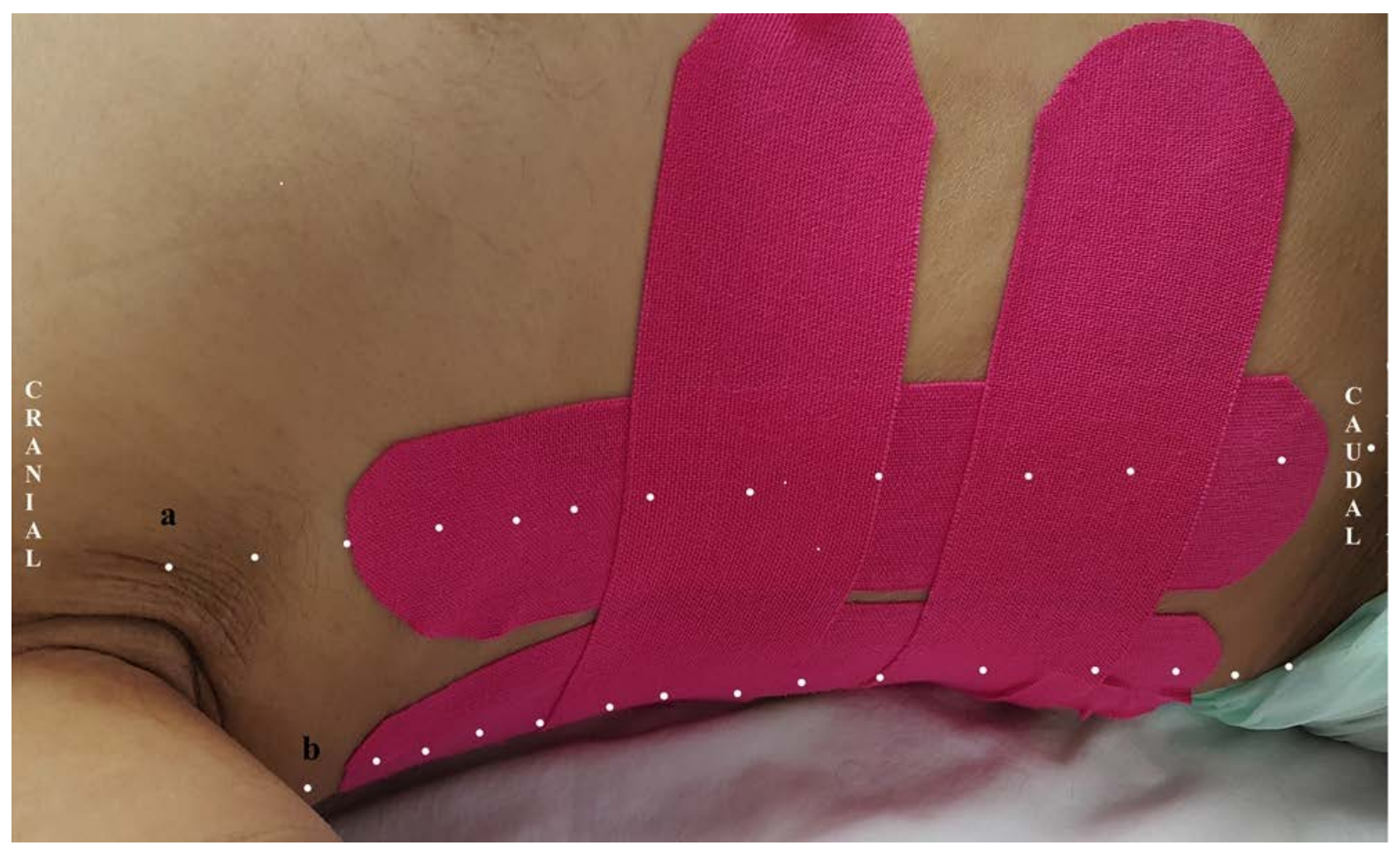

Figure 2. Kinesiotape application; anterior axillary line (a), posterior axillary line (b).

applied on the $5^{\text {th }}-6^{\text {th }}$ and $9^{\text {th }}-10^{\text {th }}$ intercostals muscles transversally and on the anterior and posterior axillary line longitudinally with $\% 50$ tension (Figure 2). The fascilitation technique was used.

\section{Ultrasound measurements}

Diaphragmatic muscle and intercostal muscles were evaluated using 7-12 $\mathrm{MHz}$ linear ultrasonography (GE LOGIQ P6 Pro Wauwatosa, U.S.A.) transducer in B-mode. While the patients were lying at a $20^{\circ}$ head-up position, US probe was placed on the anterior axillary line in the $7-8$ or $9-10$ intercostal space in sagittal position to visualize intercostal muscles and the diaphragm $[11,25,26]$. The measurements were obtained from the midline of the pleural line to the midline of the peritoneum to obtain the most accurate measurements of diaphragmatic muscle thickness (DMT) $[11,25,26]$ (Figure 3).

The percent change in diaphragm thickness (Tdi)
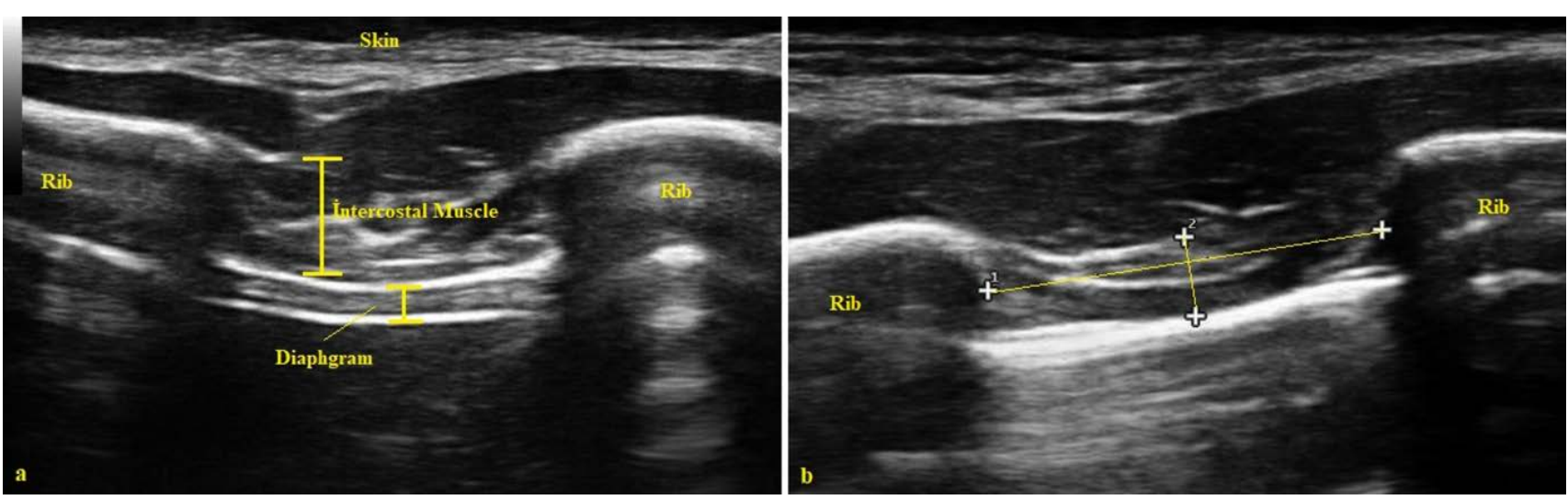

Figure 3. Ultrasonic images of diaphragm and intercostal muscles. The diaphragm muscle measurements were obtained from the midline of the pleural line to the midline of the peritoneum (a), the midpoint of the intercostal muscles between the two ribs was labeled and intercostal muscles thickness were measured at this point (b). 
between end_expiration and end_inspiration $(\Delta \mathrm{Tdi} \%)$ was calculated as (Tdi end_inspiration - Tdi end expiration / Tdi end_expiration) $\times 100$. The $\Delta$ Tdi $\%$ for each patient represented the mean of three breaths [27]. Before the measurement, kinesiotaping was removed and the physician that performed measurements was kept blind to the treatment. The same researcher, who was blind to the side of kinesiotaping application, completed third day (D3), sixth day (D6) and ninth day (D9) evaluations and recorded the data.

\section{Statistical Analysis}

Analysis of the collected data was performed using IBM SPSS 22.0 statistical package program. The Pearson chi square $\left(\chi^{2}\right)$ or Yates $\chi^{2}$ tests were used in the comparison of the categorical variables. Normal distribution of the data was tested using Shapiro-Wilk test. When it was distributed normally, independent samples $t$ test was used for between-groups comparisons and paired sample $t$ test for intra-group comparisons. Values with a probability of $(p) \alpha<0.05$ was accepted as significant.
Table 1. Demographic data of patients $(n=21)$

\begin{tabular}{lc}
\hline Characteristics & Data \\
\hline Age (year) & $42.95 \pm 6.63$ \\
Gender & \\
Male & $17(81 \%)$ \\
Female & $4(19 \%)$ \\
BMI $\left(\mathbf{k g} / \mathbf{m}^{2}\right)$ & $24.11 \pm 2.21$ \\
\hline
\end{tabular}

Data are shown as mean \pm standard deviation or number $(\%) . \mathrm{BMI}=$ Body Mass Index

\section{RESULTS}

A total of three patients were excluded from the study because two patients died and one patient was referred to an another hospital in the first three days. A total of 21 patients were evaluated at the end of the third day (D3). Eighteen patients were evaluated at the end of the sixth day (D6) because two patients were extubated and one patient died between D3-D6. Fifteen patients were evaluated at the end of the ninth day (D9) because three patients were extubated between the D6-D9. No patient was left out of the study due to any side effect of the treatment (Figure

Table 2. Comparison of the D0, D3, D6 and D9 values within the groups and between the groups

\begin{tabular}{|c|c|c|c|c|c|c|c|}
\hline & $\begin{array}{c}\text { D0 } \\
(n=21)\end{array}$ & $\begin{array}{c}\text { D3 } \\
(n=21)\end{array}$ & $\begin{array}{c}\text { (D3-D0) } \\
p\end{array}$ & $\begin{array}{c}\text { D6 } \\
(n=18)\end{array}$ & $\begin{array}{c}\text { (D6-D0) } \\
p\end{array}$ & $\begin{array}{c}\text { D9 } \\
(n=15)\end{array}$ & $\begin{array}{c}\text { (D9-D0) } \\
p\end{array}$ \\
\hline \multicolumn{8}{|l|}{ Diaphragm } \\
\hline Group 1 & $26.52 \pm 3.83$ & $24.81 \pm 3.67$ & $<0.001$ & $23.11 \pm 3.63$ & $<0.001$ & $19.93 \pm 3.51$ & $<0.001$ \\
\hline Group 2 & $25.71 \pm 4.39$ & $22.14 \pm 4.13$ & $<0.001$ & $20.33 \pm 4.10$ & $<0.001$ & $17.53 \pm 3.56$ & $<0.001$ \\
\hline$p$ & 0.528 & 0.033 & & 0.039 & & 0.074 & \\
\hline \multicolumn{8}{|l|}{ Tdi } \\
\hline Group 1 & $43.52 \pm 3.46$ & $41.95 \pm 3.38$ & $<0.001$ & $39.88 \pm 3.55$ & $<0.001$ & $38.2 \pm 3.03$ & $<0.001$ \\
\hline Group 2 & $43.62 \pm 3.04$ & $39.62 \pm 3.11$ & $<0.001$ & $37.61 \pm 2.89$ & $<0.001$ & $37.33 \pm 2.85$ & $<0.001$ \\
\hline$p$ & 0.925 & 0.025 & & 0.042 & & 0.426 & \\
\hline \multicolumn{8}{|l|}{ IMT9 } \\
\hline Group 1 & $43.38 \pm 4.51$ & $42.14 \pm 4.48$ & $<0.001$ & $40.55 \pm 4.90$ & $<0.001$ & $37.07 \pm 3.75$ & $<0.001$ \\
\hline Group 2 & $43.71 \pm 4.86$ & $39.14 \pm 4.42$ & $<0.001$ & $37.11 \pm 4.91$ & $<0.001$ & $35.60 \pm 4.48$ & $<0.001$ \\
\hline$p$ & 0.819 & 0.035 & & 0.043 & & 0.340 & \\
\hline \multicolumn{8}{|l|}{ IMT7 } \\
\hline Group 1 & $40.71 \pm 2.94$ & $39.52 \pm 2.58$ & $<0.001$ & $37.67 \pm 2.72$ & $<0.001$ & $36.20 \pm 4.07$ & 0.006 \\
\hline Group 2 & $40.57 \pm 2.93$ & $38.43 \pm 2.87$ & $<0.001$ & $35.83 \pm 2.87$ & 0.001 & $34.00 \pm 2.59$ & $<0.001$ \\
\hline$p$ & 0.876 & 0.201 & & 0.058 & & 0.089 & \\
\hline
\end{tabular}

Data are shown as mean \pm standard deviation. Independent sample test was used inter-group comparisons paired and sample test was used in intra-group comparisons. Tdi $=$ The percent change in diaphragm thickness, IMT $=$ Intercostal muscle thickness, D0 = Day 0 (pre-treatment), D3 = Day 3, D6 = Day 6, D9 = Day 9, Group $1=$ kinesiotape applied side, Group 2 (control group) = kinesio tape not applied side. 
Table 3. Comparison of the difference scores between the groups.

\begin{tabular}{|c|c|c|c|}
\hline & $\begin{array}{c}\text { D3-D0 } \\
(n=21)\end{array}$ & $\begin{array}{c}\text { D6-D0 } \\
(n=18)\end{array}$ & $\begin{array}{c}\text { D9-D0 } \\
(n=15)\end{array}$ \\
\hline \multicolumn{4}{|l|}{ Diaphragm } \\
\hline Group 1 & $-1.71 \pm 0.78$ & $-4.28 \pm 1.23$ & $-6.00 \pm 1.25$ \\
\hline Group 2 & $-3.57 \pm 0.75$ & $-5.72 \pm 1.44$ & $-7.33 \pm 1.50$ \\
\hline$p$ & $<0.001$ & 0.001 & 0.013 \\
\hline \multicolumn{4}{|l|}{ Tdi } \\
\hline Group 1 & $-1.57 \pm 0.51$ & $-3.56 \pm 1.25$ & $-5.73 \pm 2.34$ \\
\hline Group 2 & $-4.00 \pm 1.61$ & $-6.22 \pm 1.44$ & $-6.20 \pm 1.74$ \\
\hline$p$ & $<0.001$ & $<0.001$ & 0.541 \\
\hline \multicolumn{4}{|l|}{ IMT9 } \\
\hline Group 1 & $-1.24 \pm 0.54$ & $-2.83 \pm 0.92$ & $-5.47 \pm 1.46$ \\
\hline Group 2 & $-4.57 \pm 3.17$ & $-6.67 \pm 3.41$ & $-7.40 \pm 1.64$ \\
\hline$p$ & $<0.001$ & $<0.001$ & 0.002 \\
\hline \multicolumn{4}{|l|}{ IMT7 } \\
\hline Group 1 & $-1.19 \pm 0.93$ & $-2.72 \pm 2.87$ & $-4.53 \pm 5.38$ \\
\hline Group 2 & $-2.14 \pm 1.88$ & $-4.39 \pm 2.87$ & $-6.53 \pm 3.27$ \\
\hline$p$ & 0.044 & 0.090 & 0.229 \\
\hline
\end{tabular}

$1)$.

Distribution of the age, gender, and body mass index (BMI) of the patients are presented in Table 1. The pre-treatment evaluation values of the parameters in the both groups are presented in Table 2. There was no statistically significant difference between the two groups for the pretreatment evaluation parameters $(p$ $>0.05$ ).

In both groups; a statistically significant decrease was found in all the evaluation parameters at all the measurement times when compared to the pretreatment (D0) values $(p<0.05)$ (Table 2$)$.

On the D3 and D6; a statistically significant difference was found in favor of group 1 (side treated with kinesiotaping) in all the evaluation parameters except seventh intercostal muscle thickness $(p<0.05)$. The seventh intercostal muscle thickness measurements showed no statistically significant difference between the two groups $(p>0.05)$ (Table 2).

On the ninth (D9) day; there was no statistically significant difference between the two groups in all evaluation parameters $(p>0.05)$ (Table 2$)$.

In comparison of the difference scores of the two groups; a statistically significant difference was found in all the evaluation parameters for D3-D0 and in all the evaluation parameters except for the seventh intercostal muscle thickness in D6-D0, in favor of Group $1(p<0.05)$. In D9-D0, there was no statistically significant difference between the two groups in the Tdi and seventh intercostal muscle thickness $(p>0.05)$, while in the other evaluation parameters a statistically significant difference was found in favor of Group $1(p<0.05)$ (Table 3)

\section{DISCUSSION}

The present study found significantly lower diaphragmatic muscle thickness, diaphragmatic thickening fraction, and ninth intercostal muscle thickness measured on the third and sixth days in the side on which kinesiotaping were not applied. There was no significant difference in all measured parameters between the two groups on the ninth day.

Previous studies have shown mechanical ventilation-induced diaphragmatic atrophy in both humans and animals. Studies made in humans 
reported that more than $50 \%$ decrease in the crosssectional areas of type I (slow-twitch) and type II (fast-twitch) diaphragmatic fibers after mechanical ventilation for 18-69 hours [5, 27-29]. It is considered that mechanical ventilation decreases the mobility of diaphragm and immobility in turn results in diaphragmatic atrophy $[5,30,31]$. It has been reported accelerated proteolysis as a result of the suppression of diaphragmatic contractility and increase in net protein loss upon depression of protein synthesis; as a result, atrophy occurs in the diaphragmatic muscle fibers [5]. Another theory suggests that rapid increase in mitochondrial reactive oxygen species (ROS) emission caused by mechanical ventilation might play a role in the development of VIDD and that the resulting accelerated protein turnover causes rapid activation of key proteolytic systems. Increased production of ROS was found to cause an increase in protease activation and diaphragmatic atrophy $[5,30$, 31].

In the current practice, ultrasonography is commonly used to diagnose diaphragmatic atrophy [1, 31, 32]. Ultrasonographic imaging of the respiratory system was used by Cohn et al. [11] and the results of the measurements were compared with autopsy measurements. The authors reported a variability of $0.2 \mathrm{~mm}$ and suggested the use of ultrasound measurements as a reproducible, cost-effective, and non-invasive tool.

In the literature, there are many studies using US in the diagnosis and follow-up of VIDD [3, 32-34]. Schepens et al. [33] evaluated 54 patients who underwent mechanical ventilation and attempted to detect diaphragmatic dysfunction and associated risk factors using US measurements. The authors reported a $9 \%$ decline in the diaphragmatic thickness at 24 hours, $20 \%$ decline at 48 hours, and 26\% decline at 72 hours compared to baseline values. Inconsistent with the literature data, Cartwright et al. [35] reported that US measurement was not useful to demonstrate diaphragmatic weakness.

On the other hand, difficulty in weaning from mechanical ventilator is a more significant problem which seems to be the basic problem associated with VIDD [12]. Various studies have attempted to establish potential treatment strategies in order to prevent weaning problems which occurs approximately in 20 to $25 \%$ of the patients [12, 36-
38]. As pharmacological therapies to decrease ROS and diaphragmatic activity are thought to be protective against VIDD [38], various studies have used treatment strategies that focused on maintaining diaphragmatic activity [36, 37]. Diaphragm exercises have been structured and performed as inspiratory muscle training in the preoperative period [36, 37].

There are also studies which attempted to prevent VIDD and maintain contractile strength of the diaphragmatic muscle in the intensive care unit patients [12, 39]. Martin et al. [12] studied on inspiratory muscle training and evaluated patients who received mechanical ventilatory support for a mean duration of 6.5 weeks and who failed to wean from the ventilator more than once. The authors found an about $35 \%$ increase in maximum inspiratory pressure that was measured in the tracheal tube of patients in the inspiratory muscle strain training (IMST) group and they were able to wean $7 \%$ of the patients in the IMST group from mechanical ventilator. Goligher et al. [34] suggested the use of muscle preserving mechanical ventilation. The authors reported that inspiratory effort could prevent changes in the configuration of the diaphragm by titrating aeration during mechanical ventilation.

Kinesiotaping is particularly used in the treatment of musculoskeletal disorders and also in the treatment of cerebral palsy, stroke rehabilitation and postoperative pain management (thoracotomy, and video-assisted thoracoscopic surgery) [23, 24, 40, 41]. In a prospective study, Thelen et al. [23] evaluated the efficacy of kinesiotaping in patients with shoulder impingement syndrome and rotator cuff tendinitis and found a significant improvement in shoulder abduction in the kinesiotaping group. Therefore, the authors suggested that improvement in shoulder abduction could be associated with strengthening of motor unit in supraspinatus muscle due to increased proprioceptive stimulation which might, therefore, increase mobility. Jaraczewska et al. [24] evaluated the effects of kinesiotaping in hemiplegic patients in improving postural disorders of the upper extremity, balancing muscle tone and increasing muscle strength. The authors reported a decrease in muscle weakness and postural disorders and a significant improvement in upper extremity functions. Another study investigated the effects of kinesiotaping on motor functions of the upper extremity in pediatric patients 
with intracranial pathologies such as head trauma, encephalitis, brain tumor, and stroke [40]. The authors detected that occupational therapy combined with kinesiotaping provided significant improvement in motor control and functions of the upper extremity. In a study, kinesiotaping applied on the chest wall was used in the management of postoperative pain. They reported that kinesiotaping could be used as an auxiliary method in postoperative pain management [41]. However, we could not find any report evaluated the effect of kinesiotaping on the respiratory muscle thickness in the literature.

Increasing body awareness by increasing proprioception on the chest wall and aiding respiration efforts is thought to be one of the action mechanisms of kinesiotaping on the diaphragmatic muscle. Furthermore, elimination of ROS by increasing blood flow to the affected area or deceleration of muscle wasting in secondary respiratory muscles (intercostal muscles) could be possible secondary mechanisms by which diaphragmatic functions are improved. This mechanism explains lesser muscle wasting in the intercostal muscles in kinesiotaping side of the thorax in the present study. The measurements which are comparable on ninth day of the follow-up period are considered to be associated with the attempts of weaning and supporting or allowing spontaneous respiration.

\section{Limitations}

The limitations of the present study include small sample size, the use of unrecorded degree of sedation, and the use of uncontrolled positive end-expiratory pressure between 5-10 $\mathrm{cm} \mathrm{H}_{2} \mathrm{O}$.

\section{CONCLUSION}

In conclusion, our study results showed that kinesiotaping decelerated the decrease in diaphragmatic muscle and intercostal muscle thickness until sixth day during follow-up, whereas this effect was unable to be sustained after sixth day. Based on these results, although kinesiotaping alone is not sufficient in preventing VIDD, we consider that it can be used as an adjunct to other treatment methods in pulmoner rehabilitation.

\section{Informed consent}

Informed consent was obtained from all individual participants' relatives included in the study.

\section{Ethical approval}

All procedures performed in studies involving human participants were in accordance with the ethical standards of the institutional and/or national research committee and with the 1964 Helsinki declaration and its later amendments or comparable ethical standards.

\section{Conflict of interest}

The authors disclosed no conflict of interest during the preparation or publication of this manuscript.

\section{Financing}

The authors disclosed that they did not receive any grant during conduction or writing of this study.

\section{REFERENCES}

[1] Grosu HB, Lee YI, Lee J, Eden E, Eikermann M, Rose KM. Diaphragm muscle thinning in patients who are mechanically ventilated. Chest 2012;142:1455-60.

[2] Vassilakopoulos T, Petrof BJ. Ventilator-induced diaphragmatic dysfunction. Am J Respir Crit Care Med 2004;169:336-41

[3] Levine S, Nguyen T, Taylor N, Friscia ME, Budak MT, Rothenberg $\mathrm{P}$, et al. Rapid disuse atrophy of diaphragm fibers in mechanically ventilated humans. N Engl J Med 2008;358:1327-35.

[4] Berger D, Bloechlinger S, von Haehling S, Doehner W, Takala J, Z'Graggen WJ, et al. Dysfunction of respiratory muscles in critically ill patients on the intensive care unit. J Cachexia Sarcopenia Muscle 2016;7:403-12.

[5] Futier E, Constantin JM, Combaret L, Mosoni L, Roszyk L, Sapin $\mathrm{V}$, et al. Pressure support ventilation attenuates ventilator induced protein modifications in the diaphragm. Crit Care 2008;12:R116.

[6] Gayan-Ramirez G, Testelmans D, Maes K, Rácz GZ, Cadot P, Zádor $\mathrm{E}$, et al. Intermittent spontaneous breathing protects the rat diaphragm from mechanical ventilation effects. Crit Care Med 2005; 33: 2804-9.

[7] Powers SK, Wiggs MP, Sollanek KJ, Smuder AJ. Ventilator induced diaphragm dysfunction: cause and effect. Am J Physiol Regul Integr Comp Physiol 2013;305:R464-77.

[8] Mariani LF, Bedel J, Gros A, Lerolle N, Milojevic K, Laurent V, et al. Ultrasonography for screening and follow-up of diaphragmatic dysfunction in the ICU: a pilot study. J Intensive Care Med 2016;31:33843.

[9] Matamis D, Soilemezi E, Tsagourias M, Akoumianaki E, Dimassi S, Boroli F, et al. Sonographic evaluation of the diaphragm in critically ill patients. Technique and clinical applications. Intensive Care Med 2013;39:801-10

[10] Doorduin J, van Hees HW, van der Hoeven JG, Heunks LM. Monitoring of the respiratory muscles in the critically ill. Am J Respir Crit Care Med 2013;187:20-7.

[11] Cohn D, Benditt JO, Eveloff S, McCool FD. Diaphragm thickening during inspiration. J Appl Physiol 1997;83:291-6. 
[12] Daniel Martin A, Smith BK, Gabrielli A. Mechanical ventilation, diaphragm weakness and weaning: a rehabilitation perspective. Respir Physiol Neurobiol 2013;189:77-83.

[13] Orhan C, Kaya Kara O, Kaya S, Akbayrak T, Kerem Gunel M, Baltaci G. The effects of connective tissue manipulation and kinesiotaping on chronic constipation in children with cerebral palsy: a randomized controlled trial. Disabil Rehabil 2016;28:1-11.

[14] Kase K, Wallis J, Kase T. Clinical therapeutic applications of the kinesiotaping method. 2nd ed. Tokyo: Ken Ikai Co Ltd; 2003.

[15] Cools AM, Witvrouw EE, Danneels LA, Cambier DC. Does taping influence electromyographic muscle activity in the scapular rotators in healthy shoulders? Man Ther 2002;7:154-62.

[16] Morris D, Jones D, Ryan H, Ryan CG. The clinical effects of Kinesio ${ }^{\circledR} T e x$ taping: a systematic review. Physiother Theory Pract 2013;29:259-70.

[17] Lim EC, Tay MG. Kinesiotaping in musculoskeletal pain and disability that lasts for more than 4 weeks: is it time to peel off the tape and throw it out with the sweat? A systematic review with meta-analysis focused on pain and also methods of tape application. Br J Sports Med 2015;49:1558-66.

[18] Iosa M. The application of Kinesiotaping in children with cerebral palsy. Dev Med Child Neurol 2015;57:11-2.

[19] Slupik A, Dwornik M, Bialoszewski D, Zych E. Effect of Kinesiotaping on bioelectrical activity of vastus medialis muscle. Preliminary report. Ortop Traumatol Rehabil 2007;9:644-51.

[20] Chen CY, Lou MY. Effects of the application of Kinesio-tape and traditional tape on motor perception. Br J Sports Med 2008;42:513-4.

[21] Halseth T, McChesney J, DeBeliso M, Vaughn R, Lien J. The effect of Kinesiotaping on proprioception at the ankle. J Sports Sci Med 2004;3:1-7.

[22] Çeliker R, Güven Z, Aydoğ T, Bağış S, Atalay A, Çağlar Yağc1 H, et al. [The kinesiologic taping technique and its applications]. Turk J Phys Med Rehabil 2011;57:225-35. [Article in Turkish]

[23] Thelen MD, Dauber JA, Stoneman PD. The clinical efficacy of kinesiotape for shoulder pain: a randomized, double-blinded, clinical trial. J Orthop Sports Phys Ther 2008;38:389-95.

[24] Jaraczewska E, Long C. Kinesiotaping in stroke: improving functional use of the upper extremity in hemiplegia. Top Stroke Rehabil 2006;13:31-42.

[25] Sarwal A, Walker FO, Cartwright MS. Neuromuscular ultrasound for evaluation of the diaphragm. Muscle Nerve 2013;47:319-29.

[26] Ferrari G, De Filippi G, Elia F, Panero F, Volpicelli G, Aprà F. Diaphragm ultrasound as a new index of discontinuation from mechanical ventilation. Crit Ultrasound J 2014;6:8.

[27] Andrade FH, Reid MB, Westerblad H. Contractile response of skeletal muscle to low peroxide concentrations: myofibrillar calcium sensitivity as a likely target for redox-modulation. FASEB J 2001;15:309-11.

[28] Anzueto A, Peters JI, Tobin MJ, de los Santos R, Seidenfeld JJ, Moore G, et al. Effects of prolonged controlled mechanical ventilation on diaphragmatic function in healthy adult baboons. Crit Care Med 1997; 25:1187-90.

[29] Bernard N, Matecki S, Py G, Lopez S, Mercier J, Capdevila X. Effects of prolonged mechanical ventilation on respiratory muscle ultrastructure and mitochondrial respiration in rabbits. Intensive Care Med 2003;29:111-8.

[30] Burd NA, Andrews RJ, West DW, Little JP, Cochran AJ, Hector AJ, et al. Muscle time under tension during resistance exercise stimulates differential muscle protein sub-fractional synthetic responses in men. J Physiol 2012;590:351-62.

[31] Kumar V, Atherton PJ, Selby A, Rankin D, Williams J, Smith K, et al. Muscle protein synthetic responses to exercise: effects of age, volume, and intensity. J Gerontol A Biol Sci Med Sci 2012;67:1170-7. [32] Zambon M, Greco M, Bocchino S, Cabrini L, Beccaria PF, Zangrillo A. Assessment of diaphragmatic dysfunction in the critically ill patient with ultrasound: a systematic review. Intensive Care Med 2017;43:29-38.

[33] Schepens T, Verbrugghe W, Dams K, Corthouts B, Parizel PM, Jorens PG. The course of diaphragm atrophy in ventilated patients assessed with ultrasound: a longitudinal cohort study. Crit Care 2015;19:422.

[34] Goligher EC, Laghi F, Detsky ME, Farias P, Murray A, Brace D, et al. Measuring diaphragm thickness with ultrasound in mechanically ventilated patients: feasibility, reproducibility and validity. Intensive Care Med 2015;41:642-9.

[35] Cartwright MS, Kwayisi G, Griffin LP, Sarwal A, Walker FO, Harris $\mathrm{JM}$, et al. Quantitative neuromuscular ultrasound in the intensive care unit. Muscle Nerve 2013;47:255-9.

[36] Hulzebos EH, Helders PJ, Favié NJ, De Bie RA, Brutel de la Riviere A, Van Meeteren NL. Preoperative intensive inspiratory muscle training to prevent postoperative pulmonary complications in high-risk patients undergoing CABG surgery: a randomized clinical trial. JAMA 2006;296:1851-7.

[37] Nomori H, Kobayashi R, Fuyuno G, Morinaga S, Yashima H. Preoperative respiratory muscle training. Assessment in thoracic surgery patients with special reference to postoperative pulmonary complications. Chest 1994;105:1782-8.

[38] Weiner P, Zeidan F, Zamir D, Pelled B, Waizman J, Beckerman M, et al. Prophylactic inspiratory muscle training in patients undergoing coronary artery bypass graft. World J Surg 1998;22:427-31.

[39] Francis CA, Hoffer JA, Reynolds S. Ultrasonographic evaluation of diaphragm thickness during mechanical ventilation in intensive care patients. Am J Crit Care 2016;25: e1-8.

[40] Yasukawa A, Patel P, Sisung C. Pilot study: investigating the effects of kinesiotaping in an acute pediatric rehabilitation setting. Am J Occup Ther 2006;60:104-10.

[41] Imperatori A, Grande A, Castiglioni M, Gasperini L, Faini A, Spampatti S, et al. Chest pain control with kinesiology taping after lobectomy for lung cancer: initial results of a randomized placebocontrolled study. Interact Cardiovasc Thorac Surg 2016;23:223-30. 